\title{
LA JUDERÍA DE CASCANTE
}

JOSÉ LUIS LACAVE

CSIC. Madrid

Una de las kĕtûbbôt aparecidas hace unos años en Tudela, la que figura en el doc. heb. $\mathrm{n}^{0} 3$ del Archivo Municipal ', llamó mi atención por las referencias que contenía a Cascante, pequeña ciudad navarra muy próxima a Tudela $(\mathrm{a} 9 \mathrm{~km}$.), de cuya judería apenas teníamos unas cuantas noticias ${ }^{2}$.

La referida kĕtûbbâ corresponde al matrimonio de Mošeh ben Leví ben Gabbay con Solbella, hija de Šmû̉el Sar Salom, celebrado en Tudela el 14 de marhešwan del año 5247 (13 de octubre de 1486). Tanto la familia Gabbay como la de Sar Salom, son bien conocidas y con frecuentes cargos dirigentes en la aljama tudelana ${ }^{3}$. Pero en la mattanâ lěhû́ que recoge la kĕtûbbâ, el contrayente dona a la contrayente una casa que tiene en Cascante y una viña, que asimismo posee, en el término cascantino de Agüelas, lo que hace suponer que Mošeh ben Gabbay residía en esta ciudad de Cascante o al menos que aquí iba a residir el nuevo matrimonio.

La casa donada en Cascante lindaba: por un lado, con casa de Miguel Adar; por otro, con las casas de la Abadía 4; por el tercero, con casa de Abraham bar Yôm Tôb Leví; y por el cuarto, con la calle pública, donde estaba la entrada. Por su parte, la viña, sita en Cascante, en el término de Agüelas, lindaba: por un lado, con viña

\footnotetext{
1 Véase José Luis LACAVE, Importante hallazgo de documentos hebreos en Tudela, "Sefarad" XLIII (1983) 169-179, esp. 172-3.

2 Véase más adelante las citas que hacemos de Kayserling, Baer y Leroy.

3 V. Béatrice Leroy, Recherches sur les Juifs de Navarre à la fin du Moyen Âge, «Revue des Études Juives» CXL (1981) 319-432, passim. Existe versión española de este trabajo: Mercedes GARCIA-ARENAL - Béatrice LeRoy, Moros y judíos en Navarra en la baja Edad Media, Madrid, 1984, págs. 145-257.

4 Así, en aljamiado, se escribe en el documento hebreo que contiene la kětubbba.
} 
de Yiş̧̧aq Nazir ha-Gadôl («el Grande», creo que aquí equivalente a «el Viejo» o «el Mayor»); por otro lado, con viña de Pero García; y por el tercero, con la carrera vezinal ${ }^{5}$. La casa está libre de toda carga ${ }^{6}$, mientras que la viña paga una renta anual de 16 dineros débiles ala iglesia del dito lugar ', es decir, a la iglesia de Santa María, de Cascante. Digamos por último que son testigos de la mattanâ lęhûu, y de la kẹtûbbâ, los tudelanos Yacaqob bar Yěhûdâ de la Rabiça, notario de la aljama, y Yacaqob Gormezano.

Todos estos datos suscitaron en mí el interés por situar la casa de Mošeh ben Gabbay en el plano de la ciudad de Cascante, así como el de investigar algo más sobre la judería cascantina. Con esta intención me trasladé a Cascante y Tudela en mayo de 1989, con idea de proseguir luego mi invetigación en Pamplona, en el Archivo General de Navarra. En Tudela pensaba buscar en su rico Archivo Municipal cuando el archivero, mi buen amigo Julio Segura, puso en mi conocimiento el libro de Juan Ignacio Fernández Marco, Cascante, ciudad de la Ribera ${ }^{8}$, que contenía abundantes referencias a judíos cascantinos, exhumadas fundamentalmente del Archivo del Cabildo de Cascante y de la Cámara de Comptos del Archivo General de Navarra.

Así pues, sin perjuicio de seguir más adelante las investigaciones, me ha parecido interesante para los lectores de Sefarad recoger y reunir aquí, de forma ordenada y coherente, los datos que hoy se pueden conocer acerca de los judíos de Cascante (a base fundamentalmente del libro citado), añadiendo algunos comentarios.

Nada sabemos, respecto a los judíos, de la época musulmana de Cascante. Dado que esta pequeña ciudad se hallaba en la esfera de influencia de Tudela, la cual contaba con importante judería, es de suponer que algunos judíos vivieran en ella. De ser así, al tiempo de

\footnotetext{
${ }^{5}$ Es el mismo caso de la nota anterior.

${ }^{6}$ Son casas francas e quitas de toda carga, dice el doc., con esas palabras en aljamiado.

7 V. n. 4.

${ }^{8}$ Volumen primero. Pamplona, Diputación Foral de Navarra, 1978.
} 
la conquista por los cristianos ${ }^{9}$ se les aplicarían las bien conocidas capitulaciones de Tudela ${ }^{10}$ y los privilegios de los judíos de Nájera ".

La primera noticia que relaciona directamente a Cascante con judíos es de junio de 1174. Se trata de un documento por el que Pedro de Cascante, hijo de Juan Díaz, y su mujer doña Alvira entregan en prenda una propiedad en dicha ciudad a Juçef, hermano de don Abolfaçan, y sus hijos ${ }^{12}$, sin duda a causa de un préstamo. Estos hermanos, don Abolfaçan y don Juçef, así como el hijo de éste, don Muça, son judíos de Tudela que aparecen en varios documentos de compraventa relativos a esta ciudad y sus alrededores por esta época. El primero de ellos además parece ser un dirigente de la judería tudelana ${ }^{13}$. En el siglo XIV Abolfazán es un nombre de familia bien consolidado y asentado en Pamplona ${ }^{14}$.

Las siguientes noticias son de comienzos del siglo XIV y en ellas tenemos ya indicios de judíos que viven en Cascante. Así, en 1306 una doña María vende a un judío llamado Salomón una mitad de casas

"las quales son en el barrio [cascantino] del Pontarron" is.

$\mathrm{Y}$ por entonces, otro judío llamado Alcalí poseía una pieza en el término, asimismo cascantino, de Fibanco ${ }^{16}$.

A mediados del siglo XIV tenemos ya una comunidad judía amplia y bien constituida en Cascante. Para esta época tenemos un

${ }^{9}$ Cascante fue conquistada el mismo año que Tudela, 1119. V. J. M. LACARRA, Historia del reino de Navarra en la Edad Media, Pamplona, 1976, págs. 150 ss. y J. I. Fernández Marco, Cascante, ciudad de la Ribera, vol. I, Pamplona, 1978, pág. 52.

10 Así lo entiende también FernÁndez MARCo, ob. cit. (en adelante citaremos este libro por las siglas F.M.), págs. 52 ss. Cascante aparece citado, aplicándoselo, en el fuero de Tudela: v. F.M., págs. 52 y 55 y cfr. T. MuÑoz y RORMERO, Colección de fueros municipales y cartas pueblas, t. I, Madrid, 1847, pág. 418.

"Sobre la situación de los judíos tudelanos en este momento, con un análisis de las capitulaciones, v. Y. BAER, Historia de los judios en la España cristiana, trad. española de José Luis LACAVE, Madrid, 1981, t. I, págs. 42-43.

12 F. BAER, Die Juden im christlichen Spanien. I. Aragonien und Navarra, Berlín, 1929, doc. 577, págs. 929.

${ }^{13}$ F. BaER, Die Juden, doc. 577 y pág. 933. Véase también del mismo autor, Historia de los judíos, II, pág. 673, n. 30.

14 Véase el índice de nombres propios de Garcla-Arenal - Leroy, ob. cit., pág. 251 s. v. "Abolfazán, familia" y las llamadas que allí se hacen.

15 F.M., pág. 318 y n. 19.

${ }^{16}$ F.M., págs. 65, 201 y 339. Se trata de un doc. fechado el 12 de mayo de 1303. 
documento precioso que nos proporciona abundantes datos. Se trata del Libro del Monedaje de 1353 que se conserva en el Archivo General de Navarra, Cámara de Comptos, registro núm. $74{ }^{17}$.

Según este importante documento, en el año 1353 Cascante contaba con 200 hogares o vecinos. De ellos, 17 eran de hidalgos, 107 de labradores cristianos, 30 de moros, 24 de judíos y 17 clérigos. Es decir, que había 24 familias judías, lo que suponía el $12 \%$ de la población total, algo menos que los moros ${ }^{18}$. Pero además, el Libro del Monedaje nos proporciona en una lista los nombres de los judíos cascantinos, que Fernández Marco extrae por orden alfabético ${ }^{19}$. Ésta es la lista.:

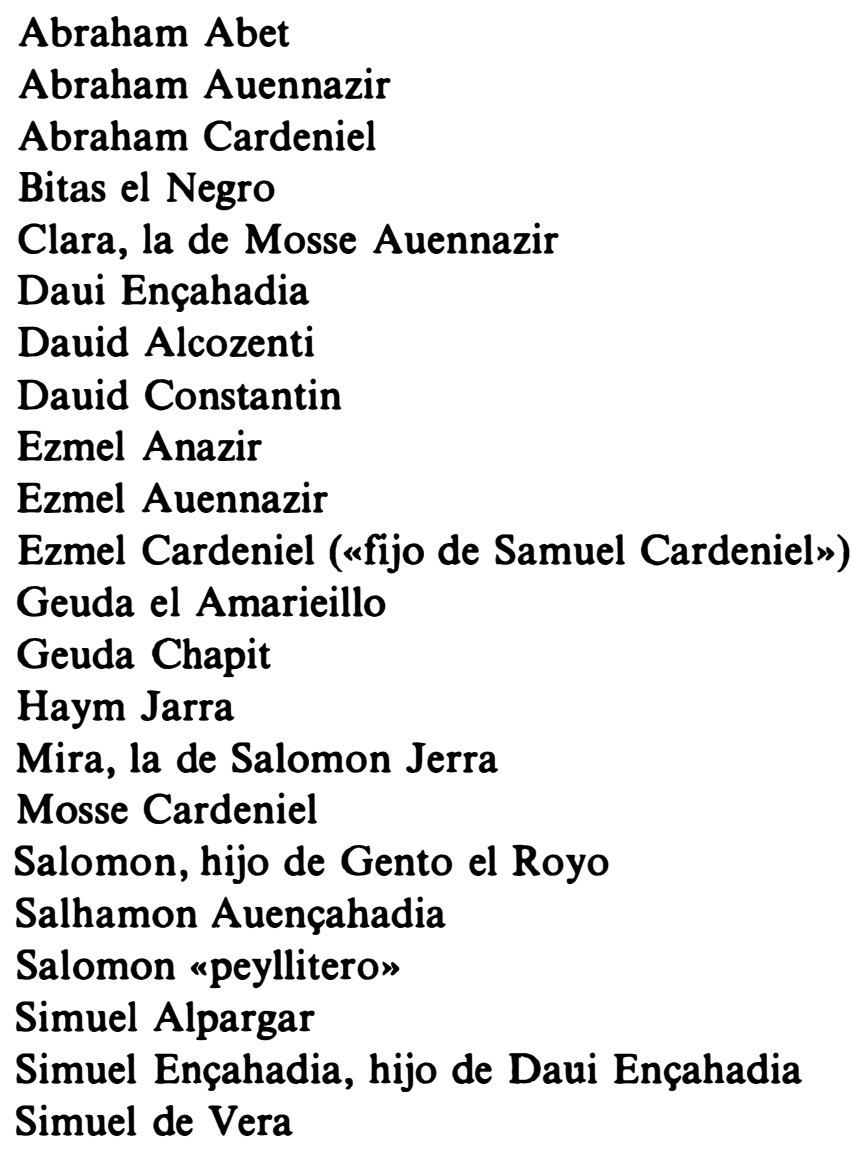

${ }^{17}$ El título completo es: «Libro del Monedage de Tudela con expresión de los que mantenían fuego». Lo publicó José Javier URANGA en su trabajo Libro del Monedage de Tudela, "Príncipe de Viana» 84-85 (1961) 139-176 y 86-87 (1962) 243-289. El monedaje de Cascante ocupa en el doc. original los folios 26r-33r y F.M. lo ha estudiado de nuevo, directamente del original. A él seguiremos en nuestras citas y comentarios.

18 F.M., pág. 385.

19 F.M., pág. 339. 
Sol, la de Simuel Cardeniel

Yento Auençahadia

Yento Açafar

Yuçe de Alfaro

Yuçe Auen Rabi

Yuçe Barquex

Yuçe Çauçala

Yuçe el Franquo

Lo primero que se echa de ver en esta lista es que hay tres troncos familiares abundantemente representados: los Nazir, Anazir o Avennazir (Abraham, 2 Ezmel y Mosse); los Cardeniel (Abraham, Ezmel, Mosse y Simuel); y los Ençahadia o Avençahadia (Daui, Salhamon, Simuel y Yento). De estos tres nombres de familia, Cardeniel lo vemos extendido por Navarra ${ }^{20}$; en cambio Nazir, Anazir o Avennazir y Ençahadia o Avençahadia sólo los encontramos en Cascante ${ }^{21}$. Recordemos que un Yishaq Nazir el Mayor es propietario de una viña en el término de Agüelas en 1486, según la $k e \check{t}$ túbbâ que hemos comentado al principio de este artículo; y aún veremos otros miembros de esta familia en ese siglo $\mathrm{XV}$, lo que quiere decir que los Nazir estuvieron muy afincados en Cascante.

De otros nombres de familia de nuestra lista, Abet lo encontramos en Tudela en los siglos XIII y XIV y en Pamplona en esta última centuria ${ }^{22}$; Amarillo o Amarieillo es apellido bien afincado en Tudela ${ }^{23}$; Jarra o Jerra lo hallamos en Pamplona por estos

${ }^{20}$ En Pamplona reside un Mosse Encardeniel en 1349 (cfr. Garcia-Arenal LEROY, ob. cit., doc. VII, pág. 211), contemporáneo, por tanto, de los Cardeniel cascantinos de nuestra lista; en Tudela un Gento Cardeniel en 1381 (cf. ibid., doc. XVI, pág. 221); y en Sangúesa un Juda en Cardeniel es «goarda de la imposición en la villa y merindad" en 1367 (cf. BAER, Die Juden, I, doc. 596).

${ }^{21}$ Miembro de la aljama de Zaragoza es un don Gento Nazir en 1332: cf. BAER, Die Juden, I, doc. 199.

${ }^{22}$ Un Mosse Abet reside en Tudela en 1265 (cf. BAER, Die Juden, I, doc. 584, pág. 943) y un Juçe Abet forma parte de la aljama tudelana en 1381 (cf. GARCIA-ARENAL - LEROY, ob. cit., doc. XVI, pág. 221); en Pamplona tenemos un Jacob Abet en 1349 (cf. ibid., doc. VII, pág. 211), contemporáneo de nuestro Abraham Abet cascantino, y un Mosse Abet en 1389 (cf. ibid., doc. XXX, pág. 233).

${ }^{23}$ Un "Samuel fillo de Jentho Amarieyllo" fue herido de una cuchillada en Tudela por Açach Torreyllon hacia 1343 (cf. ibid., doc. V, pág. 207); Alazar, Saçon y Vidal Amarillo forman parte de la aljama tudelana en 1381 (cf. ibid., doc. XVI, pág. 221) y por los mismos años, al menos de 1380 a 1394, Samuel Amarillo o Amarieillo es, junto con otros judíos de Tudela, recaudador de tributos del reino de Navarra (cf. ibid., doc. XXXI, págs. 235-236 y BAER, Die Juden, I, págs. 970, 979, 980 y 993). 
mediados del siglo XIV, como en Cascante ${ }^{24}$; Barquex quizá sea lo mismo que Bauques que aparece en Tudela en el siglo XIII y que Batquix, también de Tudela en el siglo XV ${ }^{25}$. Por su parte, Constantin es un apellido muy conocido de judíos aragoneses. En cuanto a "el Royo", era apelativo bastante frecuente entre los judíos navarros.

En el Libro del Monedaje, la lista de judíos de Cascante la encabeza Juçe o Yuçe de Alfaro. De ahí deduce Fernández Marco ${ }^{26}$ que quizá fuera el principal. Es posible, en efecto, que tuviera un cargo dirigente en la comunidad, pues como veremos enseguida parece ser un rico propietario.

Efectivamente, el citado Libro nos informa también, en parte, de las propiedades de los cascantinos, pues los comisarios que lo redactan indagan si desde el monedaje anterior se han producido transacciones de propiedad. Al recoger las casas y fincas que han sido objeto de transacción, no sólo se consignan el vendedor y el comprador, sino que se dan también sus lindes, con lo que nuevos propietarios aparecen anotados. De entre todos éstos hay unos cuantos judíos, que pasamos a reseñar.

El más hacendado de los judíos de Cascante parece era Simuel Çahadia, hijo de Daui Ençahadia. Hasta quince piezas y una viña, situadas en distintos términos cascantinos, le había vendido para 1353 al alcalde Semén Cunchillos ${ }^{27}$. Además, aparece como propietario de una pieza en el término de Fibanco ${ }^{28}$ y de dos viñas en la Torrecilla ${ }^{29}$. Es de suponer que esto era sólo una parte de sus propiedades.

También Juçe de Alfaro debía de ser hacendado; a Martín Xemeniz de Calchetas le había vendido una viña y seis piezas, todas

\footnotetext{
${ }^{24}$ Un Juda Jarra, con su hermana Soli, pagaba una multa cuando vivía en el barrio de la Navarrería en 1349 (cf. GARCiA-ARENAL - LEROY, ob. cit., doc. VII, pág. 211) y probablemente el mismo personaje con el nombre de Judas Jerra paga tributos sobre la carnicería de los judíos en ese mismo barrio en 1333 (cf. ibid., doc. I, pág. 202).

${ }^{25}$ Un Gento Bauques reside en Tudela en 1265 (cf. BAER, Die Juden, I, pág. 947) y un Rabi Samuel Batquix posee una viña en el término tudelano carrera del Alfaquí en 1459 (cf. GARCfA-ArenAL - LeROY, ob. cit., doc. XXXVI, pág. 246).

26 F.M., págs. 339 y 385.

${ }^{27}$ F.M., pág. 386, n. 11.

${ }^{28}$ F.M., pág. 201.

29 F.M., pág. 219.
} 
en el término de Lor ${ }^{30}$. Asimismo es de suponer que esto era sólo una parte de sus posesiones. Bitas el Negro le había vendido una viña y una pieza a Miguel de Alfaro ${ }^{31}$. Y Ezmel Anazir le había vendido al alcalde Semén Cunchillos unas casas en la Plaza ${ }^{32}$, sin duda el lugar más céntrico de Cascante. Además, aparecen como propietarios en 1353 los siguientes: Mosse Cardeniel y Simuel de Vera poseen casas ${ }^{33}$, Juçe el Franquo casas y viñas francas ${ }^{34}$ y Yuçe de Çauçala una pieza ${ }^{35}$.

Buena parte de estas propiedades que venden, las habían comprado los judíos no mucho antes a diversas personas, fundamentalmente caballeros, que al parecer se habían empobrecido, pues en la anotación de las transacciones se consigna el nombre del propietario anterior al judío. Es el caso de las ventas realizadas por Juçe de Alfaro, Simuel Çahadia y Ezmel Anazir. $Y$ también el de una anotación del Libro que nos informa de que Martín Xemeniz de Calchetas «compró de judíos» una pieza y una viña, así como Johan y Pedro, hijos de Sancho el Rey compraron una viña, «et compraronla de judíos"; todas estas propiedades habían sido de Yenego Periz, hidalgo. Las casas que poseen Mosse Cardeniel y Simuel de Vera asimismo habían sido de caballeros ${ }^{36}$. Cabe sospechar que se tratara de negocios especulativos.

Aún tenemos algunas noticias más sobre los judíos de Cascante en el siglo XIV. Así, en un Inventario del Archivo del Cabildo de Cascante se anota que en 1361 la dama judía doña Sol Oro poseía una casa ${ }^{37}$. Fernández Marco cree ${ }^{38}$ que sería la viuda de Simuel Cardeniel, pues en la lista del Libro del Monedaje de 1353 aparecía una «Sol, la de Simuel Cardeniel». Es posible, dada la cercanía de fechas, pero Sol y Sol Oro eran nombres muy corrientes entre las judías navarras.

Por su parte, en la Cámara de Comptos, del A.G.N., se recogen

30 F.M., pág. 264, n. 448 y pág. 405, n. 98.

31 F.M., págs. 219 y 228.

32 F.M., págs. 326 y 386, n. 11.

${ }^{33}$ F.M., pág. 387.

34 F.M., pág. 388.

${ }^{35}$ F.M., pág. 386, n. 11.

${ }^{36}$ F.M., pág. 387.

37 Fol. 13v: 4 septiembre 1361. Véase F.M., pág. 339 y n. 147.

${ }^{38}$ F.M., pág. 339. 
varias noticias relativas a pechas y rentas reales de Cascante y sus judíos. En 1378 Carlos II hizo donación del castillo y villa de Cascante a un primo suyo, el caballero don Roger Bernart de Foix, pero reservándose para sí las pechas de los judíos y la jurisdicción sobre ellos ${ }^{39}$. Años después, en 1388, Carlos III el Noble asignaría a su esposa, doña Leonor de Trastámara, 18.000 florines de Aragón anuales, de los que 6.000 serían sobre las pechas de los judíos del reino navarro, mencionándose Cascante ${ }^{40}$. Por otro lado, el tudelano Samuel Amarieillo - que con otros socios había arrendado las rentas reales de Navarra - subarrendó en 1389 el molino que el rey poseía en Cascante ${ }^{41}$. Y en 1394 el señor de Cascante, Hurtado de Mendoza, mayordomo de Castilla, constituyó por su procurador en las cosas concernientes a Cascante al judío tudelano Semuel Bienvenist ${ }^{42}$, quien en 1396 y 1399 acusaría recibo de las rentas ordinarias de la villa ${ }^{43}$.

Pero también tenemos noticias de judíos ejerciendo oficios, concretamente de tres maestros albañiles y dos peones. Entre marzo y junio de 1384 se llevaron a cabo obras de reparación en el castillo de Cascante. Las obras de cantería fueron encomendadas a tres "maestros mazoneros" judíos venidos expresamente de otra parte: Simuel picador, el "Tronpero" y el "Ganador" ${ }^{44}$. Probablemente serían de Tudela, la ciudad grande cercana; desde luego en 1370 un "Samuel picador" figura entre los propietarios judíos tudelanos que se beneficiaban de un derecho de uso del agua ${ }^{45}$. Entre el peonaje de estas obras del castillo aparecen dos judíos: Mosse Cardeniel y Açafar ${ }^{46}$. Recordemos que en la lista del Libro del Monedaje de 1353 figuraban un Mosse Cardeniel y un Yento Açafar. Quizá fueran los mismos, aunque haya treinta años de diferencia; en el caso del primero podría también tratarse de un nieto ${ }^{47}$. El docu-

${ }^{39}$ F.M., pág. 73 y n. 62 de pág. 74.

${ }^{40}$ F.M., pág. 80 y n. 80.

${ }^{41}$ F.M., pág. 292.

42 F.M., pág. 85.

${ }^{43}$ F.M., pág. 87.

44 F.M., págs. 117 y 393.

${ }^{45}$ Cf. B. LeROY, Recherches pág. 338, n. 46.

${ }^{46}$ F.M., pág. 393.

${ }^{47}$ F.M. piensa que serían hijos, pero no es probable que el padre y el hijo llevaran el mismo nombre - Mošeh-, aunque es cierto que tengo recogidos unos cuantos casos de este tipo en Navarra y Aragón. 
mento que nos proporciona estos datos acerca de las obras de reparación del castillo ${ }^{48}$, nos informa también de que los mazoneros judíos descansaban el sábado y trabajaban en domingo ${ }^{49}$ y de que, como especialistas que eran, cobraban un salario doble que el de los peones; concretamente Simuel Picador y el «Tronpero" ganaban seis sueldos, mientras que el "Ganador» cobraba cinco, lo mismo que el maestro carpintero, un cristiano de Cascante ${ }^{50}$.

Las siguientes noticias que tenemos de los judíos de Cascante son ya de mediados del siglo XV. En 1443 «Helehazar Mataron judío" censaba una pieza en cierto término cascantino al eclesiástico

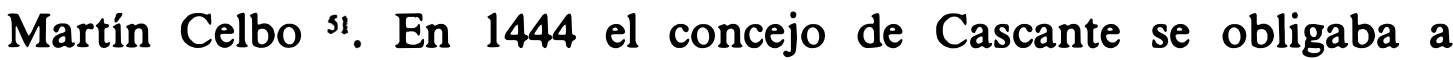
pagar ciento veinte florines a Mosse Chavatix, a quien pocos años después -1452 - el cabildo daba veinte libras ${ }^{52}$, lo cual sugiere que se dedicaba al préstamo. Probablemente gozaba de buena posición económica, pues, como veremos enseguida, por esos años era adelantado de la aljama.

En 1446 Gento Benazir era propietario de una casa en Cascante, junto a otra de un eclesiástico. En 1449 el clérigo racionero García Escudero censaba una pieza a Açach Benazir y en 1457 el párroco Juan Pérez de Sangüesa censaba un olivar a Salomón Benazir. Por último, en 1460 el párroco Ximén López compraba una casa a "Jeudatem judío" pagando dos florines de oro ${ }^{53}$.

En febrero de 1452 el monarca Juan II hacía donación del señorío de Cascante a don Diego Gómez de Sandoval, conde de Castro, quien tomaba posesión del mismo en un concejo general celebrado el 24 de octubre siguiente ${ }^{54}$. Al acto solemne, además de las autoridades correspondientes y junto a los jurados por los hidal-

48 Un cuaderno de nueve folios en el que Zalema Zaragozano, "moro maestro de las hobras del seynnor Rey" fue anotando las diversas partidas de las obras y reparaciones efectuadas en el castillo de Cascante, el cual se guarda en el A.G.N., Cámara de Comptos, caja 46, núm. 31. Véase F.M., pág. 116 y n. 51.

49 F.M., pág. 117, n. 57.

50 F.M., pág. 393.

${ }^{51}$ F.M., pág. 340. Éste y los siguientes datos los extrae Fernández Marco del Archivo del Cabildo de Cascante.

52 F.M., pág. 339.

53 Para todos ellos v. F.M., pág. 340 y cf. págs. 211 y 223.

${ }^{54}$ El A.G.N. (Comptos, caja 156, núm. 54) conserva un pergamino que levanta acta notarial de la toma de posesión del señorío. F.M., Apéndice 5, págs. 426-430, publica una transcripción de ese pergamino. 
gos, los jurados por los labradores y los representantes de los eclesiásticos, asisten los representantes de los "vezinos e moradores de la dicha villa de Cascant", entre los que se cuentan los judíos Geuda Leví, Mosse Chavatix y Açach Benazir. Sin duda asistían a tan importante acto oficial en calidad de adelantados de la aljama cascantina.

Como vemos, entre estos judíos de Cascante de quienes tenemos noticias a mediados del siglo $\mathrm{XV}$, hay un predominio de la familia Nazir o Benazir, a la que ya hemos visto bien representada en la centuria anterior. El Açach Benazir que era adelantado de la aljama en 1452 podría ser el Yișhaq Nazir ha-Gadôl de nuestra kẹtûbbâ de 1486. Aún sabemos de otro Benazir en este siglo XV, Ezmel Benazir, quien en fecha desconocida, pero posiblemente después de 1480, reconocía tener

«en encomanda de los venerables señores los vicario sagristan et razioneros de la eglesia e capitol de Santa María de Cascant noventa libras febles" "ss.

En 1494 este Ezmel era, según parece, condenado a alguna pena ${ }^{56}$.

Por otra parte, la familia Chavatix, de la que aquí teníamos un representante - Mosse Chavatix-, es familia bien afincada en Tudela al menos desde el siglo XII. En 1162 era testigo de una venta en esa ciudad Hebraim (Abraham) Chavathiz ${ }^{57}$ y entre las multas pagadas al Baile de Tudela aparecen, en 1352, Mosse y Açach - tío y sobrino-Chavatix ${ }^{58}$, y en 1367, Açaquiel Chavatis, quien pagaba caloña por quebrantar el sábado ". También los Mataron, de los que en Cascante acabamos de ver un Eleazar, parecen asentados en Tudela, de cuya aljama formaba parte en 1381 un Çahadia Mataron ${ }^{60}$.

Asimismo, se echa de ver en estas notas de mediados del siglo

ss F.M., pág. 340 y n. 153. El asiento del Inventario del Archivo del Cabildo de Cascante no lleva fecha, pero a juzgar por el folio en que está inserto debe de corresponder a una fecha superior a 1480, quizá incluso a 1490.

${ }^{56}$ F.M., pág. 340 y n. 155, escribe que «era sentenciado, sin que sepamos el motivo».

57 BAER, Die Juden, I, pág. 923.

58 Garcla-Arenal - Leroy, ob. cit., doc. IX, pág. 214.

59 BAER, Die Juden, I, pág. 972.

60 Garcia-Arenal - Leroy, doc. XVI, pág. 221. 
$\mathrm{XV}$ la intensa relación, habitual por otro lado en otras ciudades, sobre todo de Castilla, entre los judíos y el estamento eclesiástico.

La donación del señorío de Cascante al Conde de Castro incluía también, entre otras, las pechas de los judíos, que se cifraban en 130 libras anuales, de cuya percepción existen recibos hasta diez años después ${ }^{61}$. De rentas reales pagadas por los judíos cascantinos tenemos una noticia anterior, de 1426 , en que pagaban de tributo de imposición 19 libras y 10 sueldos, que entregaron al concejo ${ }^{62}$. Y poco antes de la donación al conde de Castro, en 1446, el mismo rey don Juan había hecho donación a doña Violante de Agramont, señora de Monteagudo, de las pechas "de la aljama de los judíos de Cascante» ${ }^{63}$. Es la única vez que se llama aljama a la comunidad judía de Cascante, pero creemos que tenía ya esta categoría desde el siglo anterior, pues, como hemos visto, en 1353 ya era bastante crecido el número de familias judías en la ciudad y parece que disponían de sinagoga, y es de suponer que también de las demás instituciones necesarias. En cambio en 1496, tan próxima ya la expulsión, sólo quedaban en Cascante 9 familias judías, según una noticia que ya recogió Yanguas y reprodujo Kayserling ${ }^{64}$; no es de extrañar, por tanto, que el novio de nuestra kẹtûbbâ de 1486 buscara novia en Tudela, máxime teniendo en cuenta la natural relación entre ambas ciudades tan próximas y la también natural atracción de la chica por la grande.

Esa relación y atracción, que se mantiene hoy día, se nota además en la adquisición por judíos tudelanos de tierras en Cascante. En la segunda mitad del siglo XIV varios miembros de la famosa familia judía de Tudela de los Menir poseían allí tierras, según ya sabíamos por las investigaciones de B. Leroy en el A.G.N.: Rabí Azach ben Menir y sus hijos eran propietarios de cuatro piezas y una huerta y Rabí Jeudá ben Menir de ocho piezas, un olivar y un viñedo ${ }^{65}$. Estos datos se ven corroborados por el Libro del Monedaje

${ }^{61}$ F.M., págs. 97 y 101 y n. 149; hay tres recibos de 1460, 61 y 62.

${ }^{62}$ F.M., pág. 340 y n. 160.

${ }^{63}$ F.M., pág. 338 y n. 136.

${ }^{64}$ M. KAYSERLING, Die Juden in Navarra, den Baskenlaendern und auf den Balearen, Berlín, 1861, pág. 46, n. 5; lo toma de J. Yanguas y MiRANDA, Diccionario de antigüedades del reino de Navarra, Pamplona, 1840, Adiciones, 100.

${ }^{65}$ B. LeROY, Une famille de la Juderia de Tudela aux XIII et XIVe siècles: les Menir, "Revue des Etudes Juives» CXXXVI (1977) 277-295, esp. 284-286; y cf. B. LEROY, Recherches, pág. 340. 
de 1353 a través del cual sabemos que los herederos del judío tudelano «Rabi Açach Eueminir» poseían piezas en el término cascantino de Fibanco ${ }^{66}$ y que el también tudelano Rabí Judá - posiblemente el Jeudá ben Menir antes citado- era propietario de seis piezas en diversos términos de Cascante ${ }^{67}$. Por otro lado, según el Inventario del Archivo del Cabildo de Cascante, entre las tierrás de foranos en la ciudad hacia 1470 figuran «el ortal de los judíos de la sinagoga de Tudela" con una cahizada y, con otra cahizada, un "Ezmel ben ..." ${ }^{68}$.

Este inventario del archivo cascantino nos proporciona también una curiosa noticia. Con fecha de 12 de abril de 1462 escribe:

«Protestacion de Abram de la Rabiça judio contra el vicario Ximen Lopez y alcalde y jurados de Cascante pretendiendo tenía privilegios reales para no ser excomulgado" ${ }^{69}$.

Fernández Marco cree, por aquello de la excomunión, que se trata de un converso, pero sin duda se trata aquí del herem - suele traducirse "excomunión»- que alguna comunidad judía -quizá la misma de Cascante - habría proclamado contra este Abraham. De otro modo, si fuera converso, no se entendería que siguiera llamándose "Abram de la Rabiça judío", ni que tuviera privilegios reales contra la excomunión, lo cual sí ocurría a veces contra el herem judío.

Por otro lado, este Abram de la Rabiça podría ser de Pamplona, como piensa Fernández Marco ${ }^{70}$-aunque difícilmente, sin embargo, el Abram de la Rabiça que casi cuarenta años antes (1427) los monarcas llaman su comisario para cierta avenencia con las aljamas del reino-; pero también podría ser de la cercana Tudela, pues la familia de la Rabiça es familia bien afincada en esa ciudad "; precisamente por esos años Mayr de la Rabiça era adelantado de la aljama tudelana ${ }^{72}$ y poco después era notario de la misma aljama Ya`aqob de la Rabiça, según hemos visto en la kẹtûbbâ de 1486.

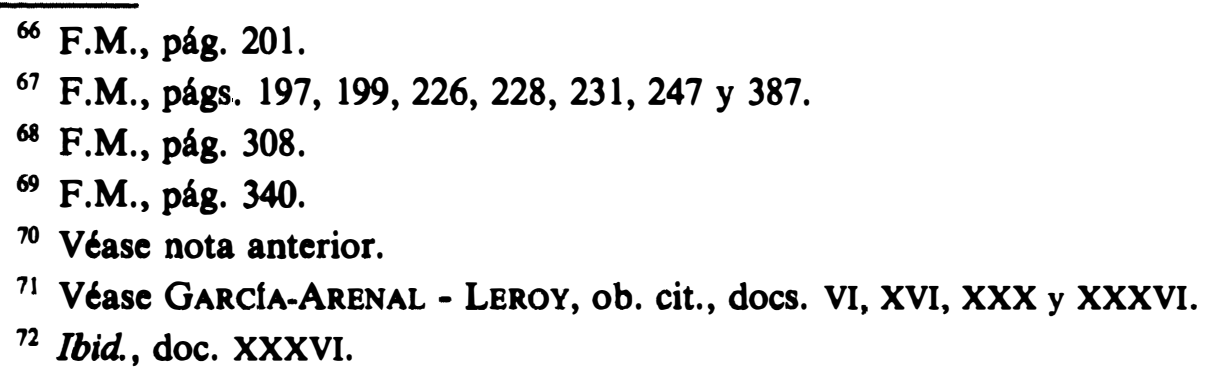




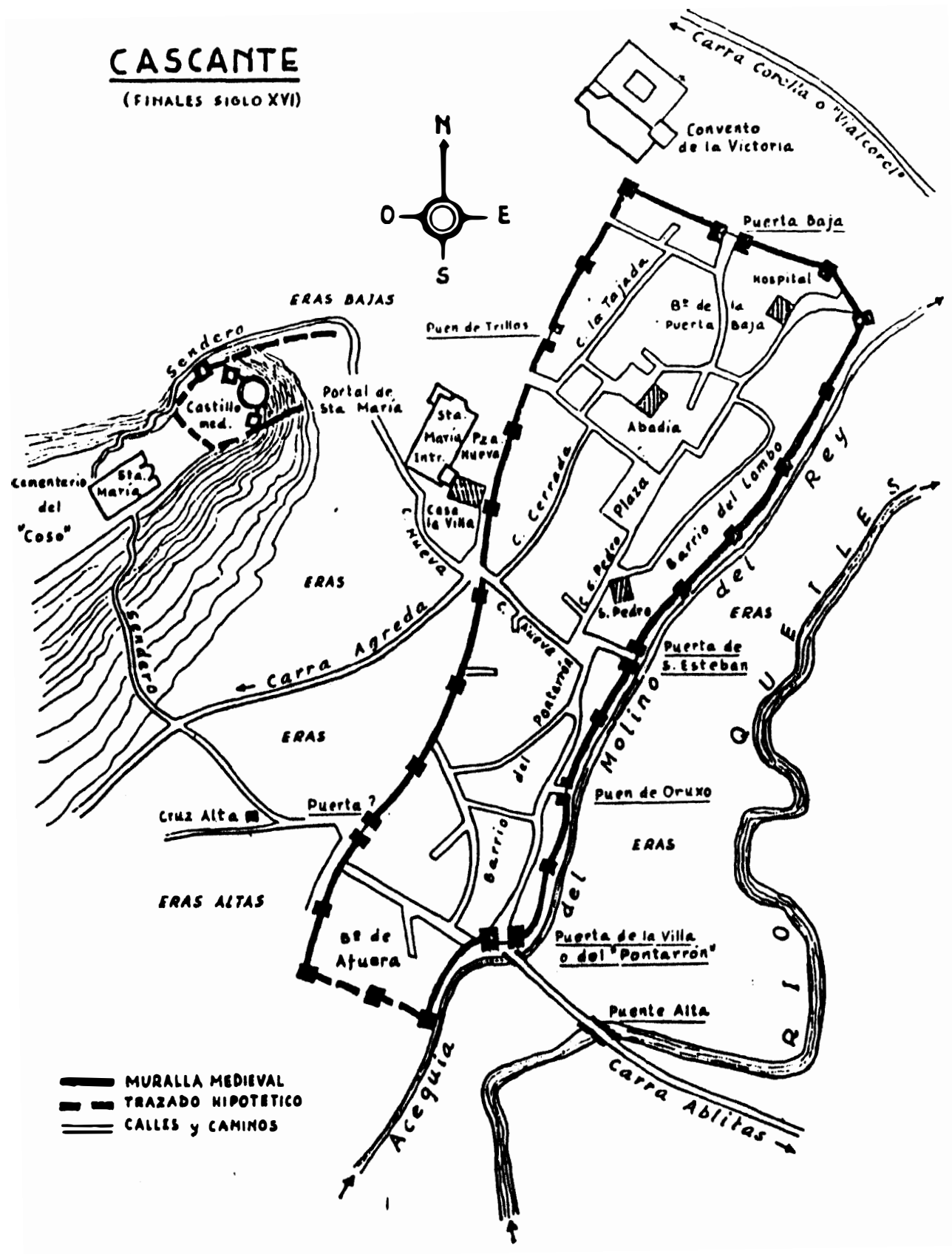




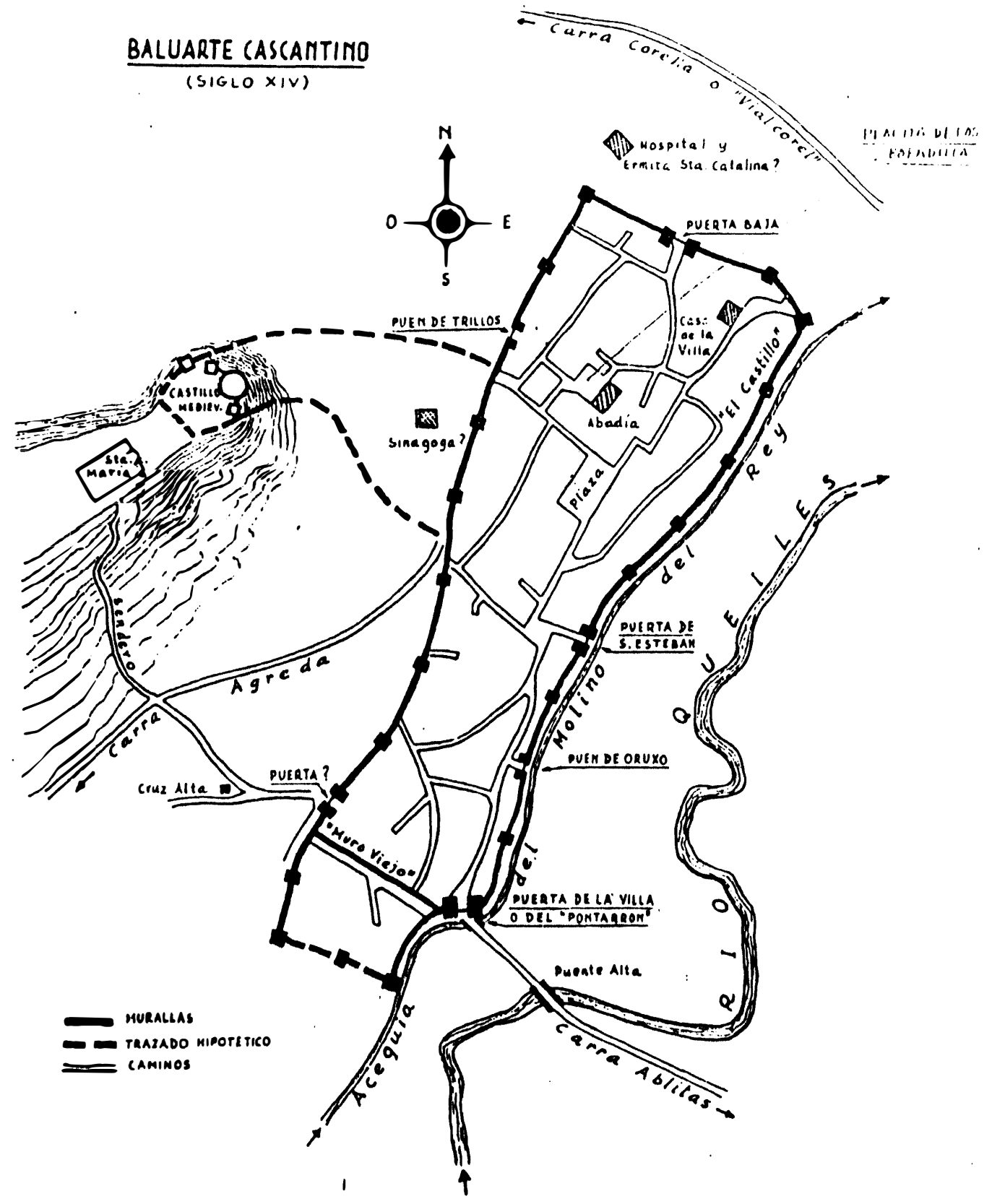


No parece que en Cascante hubiera barrio judío específico, sino que los judíos vivían entremezclados con los cristianos. La casa que el contrayente de nuestra $k e \underline{t} u \hat{b} b a$ donaba a la contrayente lindaba, como hemos visto, con la casa de Abraham bar Yôm Tôb Leví, pero también con la del cristiano Miguel Adar y con las casas de la Abadía. Así se llamaba en el siglo XV -0 también la abadía del obispo de Tarazona - a una mansión que ocupaba el solar donde hoy se alza el palacio de los Bobadilla, es decir, el lado oriental de la actual placita de los Bobadilla (v. planos de Cascante, tomados de Fernández Marco) ${ }^{73}$. También la primera casa que hemos mencionado de un judío en Cascante, la de Salomón en 1306 en el barrio del Pontarrón (v. la localización de este barrio en el plano del siglo XVI), lindaba con la casa de un cristiano ${ }^{74}$. $\mathrm{Y}$ asimismo ocurría con las casas que en el siglo XIV poseían Mosse Cardeniel y Simuel de Vera ${ }^{75}$ y con la que en el siglo XV tenía Gento Benazir ${ }^{76}$, mientras que las casas que Ezmel Anazir le había vendido al alcalde en 1353 en la céntrica Plaza (v. planos) lindaban con "casas de la capellanía" ". Así pues, parece claro que no podemos hablar en Cascante de una judería o barrio judío aparte en ningún momento.

En cuanto a la sinagoga, por un privilegio datado en 1498 y otorgado por Juan III Albret y Catalina de Foix, los monarcas accedían a la petición de la villa de Cascante donándole «la sinagoga de los judíos de la dicha villa por el destierro a ellos impuesto" para edificar «d'ella y en ella» una iglesia de «invocación que fuesse la deuocion de la dicha villa" ${ }^{78}$. Y todavía en 1514 se menciona una donación de censos y tributos pertenecientes al rey «en las sinagogas y almosnas" de los judíos de Tudela, Cascante y demás poblados de la merindad ${ }^{79}$.

Esa iglesia que se edificó en el solar que ocupaba la sinagoga es la actual parroquia de Cascante, la iglesia de la Asunción edificada en el siglo XVI (v. en el plano del s. XVI, en la Plaza Nueva, junto a

\footnotetext{
${ }^{73}$ F.M., págs. 99 y 329; los planos, del s. XIV y del s. XVI, en págs. 124 y 334.

${ }^{74}$ F.M., pág. 318, n. 19.

${ }^{75}$ F.M., pág. 386.

${ }^{76}$ F.M., pág. 340.

77 F.M., pág. 326.

${ }^{78}$ El privilegio se publicó en la revista "El Romero", núm. 78 (sept. 1925) 10-12. Véase F.M., pág. 338 y n. 137.

79 F.M., pág. 338 y n. 137.
} 
la actual Casa de la Villa o Ayuntamiento). Antes de la expulsión de los judíos la parroquia de Cascante era la iglesia de Santa María, situada bastante extramuros, junto al castillo (v. planos), donde hoy está la iglesia del Romero, en un alto de acceso algo dificultoso.

Terminaremos este trabajo con una nota un tanto curiosa. En 1594, casi cien años después de la expulsión, vivía en Cascante y tenía una casa en la calle Cerrada un cierto Bueno Mataron. Pudiera ser -escribe Fernández Marco ${ }^{80}$-y nosotros creemos con él一 un converso descendiente del Eleazar Mataron que, según hemos visto ${ }^{81}$, censaba en 1443 una pieza a un eclesiástico.

\section{RESUMEN}

Una $k e ́ t u b b a ̂$ hallada hace pocos años en la que el contrayente dona a la contrayente una casa y una viña que posee en Cascante da pie al autor para recoger y comentar los datos que se tienen acerca de la judería de esa pequeña ciudad navarra, muy próxima a Tudela. Se estudian las familias judías cascantinas y se pone de relieve la localización de la sinagoga de Cascante y de algunas casas de judíos.

\section{SUMMARY}

A ketúbba found a few years ago in which one contracting party (the man) bestowed on the other contracting party (the woman) a house and a vineyard he possessed in Cascante, provides the author with the means of collecting and commenting on the data known about the Jewry of that small city of Navarra, close to Tudela. The Jewish families of Cascante are studied and the location of the synagogue and some houses belonging to Jews are particularly emphasized.

${ }^{80}$ F.M., pág. 340 y n. 157.

${ }^{81}$ Arriba, pág. 327. 